\title{
Square Difference Labeling for Some Graphs
}

\author{
J.Shiama \\ Assistant Professor \\ Department Of Mathematics \\ Cms College of Science and Commerce \\ Coimbatore -641049, Tamilnadu, India
}

\begin{abstract}
Here I define a new labeling and a new graph called square difference labeling and the square difference graph. Let $\mathrm{G}$ be a $(p, q)$ graph. $G$ is said to be a square difference graph if there exists a bijection $\mathrm{f:} V(\mathrm{G}) \rightarrow\{0,1, \ldots, \mathrm{p}-1\}$ such that the induced function $\mathrm{f}^{*}: \mathrm{E}(\mathrm{G}) \rightarrow \mathrm{N}$ given by $\mathrm{f}^{*}(\mathrm{uv})=\mid[\mathrm{f}(\mathrm{u})]^{2}$ $[\mathrm{f}(\mathrm{v})]^{2} \mid$ for every uv $\in \mathrm{E}(\mathrm{G})$ are all distinct. A graph which admits square difference labeling is called square difference graph. In this paper I discussed the square difference labeling is admitted for some graphs like cycles, complete graphs, cycle cactus, ladder, lattice grids, wheels, quadrilateral snakes, the graph $\mathrm{G}=\mathrm{K}_{2}+\mathrm{m} \mathrm{K}_{1}$.
\end{abstract}

\section{Keywords}

Square difference labeling, square difference graph, cycle cactus.

\section{INTRODUCTION}

If the vertices of the graph are assigned values subject to certain conditions is known as graph labeling and have been motivated by their utility to various applied fields and their intrinsic mathematical interest. Graph labeling was first introduced in the mid sixties. A dynamic survey on graph labeling is regularly updated by Gallian [4] and it is published by Electronic Journal of Combinatory. Vast amount of literature is available on different types of graph labeling and more than 1000 research papers have been published so far in past three decades.

The present work is aimed to discuss one such a labeling namely square difference labeling this labeling is defined by me.

The brief summary of definitions and other information which are necessary for the present investigation are given below. Beginning with simple, finite, connected and undirected graph $\mathrm{G}=(\mathrm{V}(\mathrm{G}), \mathrm{E}(\mathrm{G}))$ with $\mathrm{p}$ vertices and $\mathrm{q}$ edges. For all other terminology and notations in graph theory I follow West [9].

The square sum labeling and square sum graphs are [1] are defined and discussed by V.Ajitha, S.Arumugam and K.A.Germina.They proved that the cycle, complete graph Kn, , the cycle cactus, ladder and complete lattice grids are square sum graphs.In a similar way L.Beineke and S.M.Hegde[2] proved that some graphs are strongly multiplicatively indexable. The square sum labeling for some middle and total graphs [6] is taken for references.

Definition 1.1. A cactus is a connected graph in which any two simple cycles have at most one vertex in common. Equivalently, every edge in such a graph belongs to at most one simple cycle. Equivalently, every block (maximal sub graph without a cut-vertex) is an edge or a cycle.

\section{MAINRESULTS}

Definition2.1: Let $\mathrm{G}=(\mathrm{V}(\mathrm{G}), \mathrm{E}(\mathrm{G}))$ be a graph. $\mathrm{G}$ is said to be square difference labeling if there exist a bijection $\mathrm{f}$ : $\mathrm{V}(\mathrm{G}) \rightarrow\{0,1,2, \ldots . \mathrm{p}-1\}$ such that the induced function $\mathrm{f}^{*}: \mathrm{E}(\mathrm{G})$ $\rightarrow \mathrm{N}$ given by

$$
f^{*}(u v)=\left|\left[f^{*}(u)\right]^{2}-\left[f^{*}(v)\right]^{2}\right|
$$

for every $u v \in E(G)$ are all distinct.

Definition2.2: Any graph which admits square difference labeling is called square difference graph.
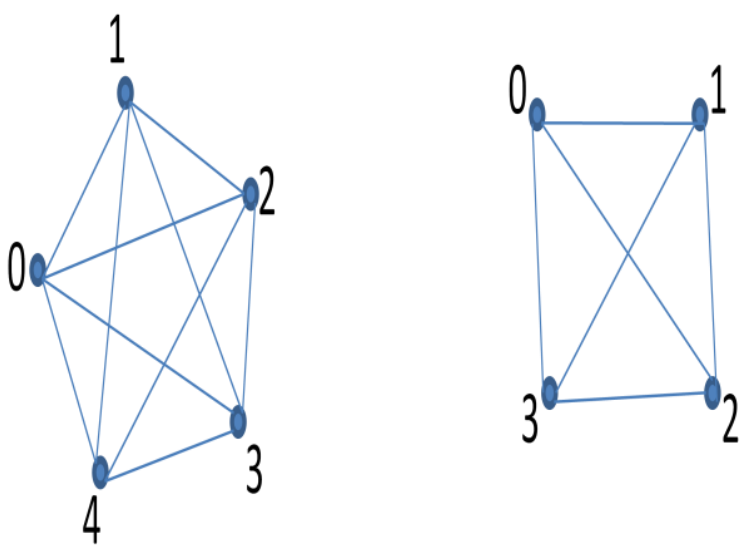

Fig 1: square difference labeling of $k_{5} \& k_{4}$

Theorem 2.3: Let $G=(V, E)$ be a $(p, q)-$ graph which is square difference graph with the square difference labeling $\mathrm{f}$. Then $\prod f *(e)$ can be represented as the difference of two squares.

Proof: Let $\mathrm{G}$ be a graph having $\mathrm{f}\left(\mathrm{u}_{1}\right)=\mathrm{a}, \mathrm{f}\left(\mathrm{v}_{1}\right)=\mathrm{b}, \mathrm{f}\left(\mathrm{u}_{2}\right)=\mathrm{c}$ and $\mathrm{f}\left(\mathrm{v}_{2}\right)=\mathrm{d}$. Then by the definition of square difference labeling $\mathrm{f}^{*}\left(\mathrm{e}_{1}\right)=\mid\left[\mathrm{f}\left(\mathrm{u}_{\mathrm{i}}\right)\right]^{2}$ $\left[\mathrm{f}\left(\mathrm{v}_{\mathrm{i}}\right)\right]^{2} \mid$ we have $\quad \mathrm{f}^{*}\left(\mathrm{e}_{1}\right) \mathrm{f}^{*}\left(\mathrm{e}_{2}\right)=\left|\left[\mathrm{f}\left(\mathrm{u}_{1}\right)\right]^{2}-\left[\mathrm{f}\left(\mathrm{v}_{1}\right)\right]^{2}\right|$ $\left|\left[f\left(u_{i}\right)\right]^{2}-\left[f\left(v_{i}\right)\right]^{2}\right|=\left(a^{2}-b^{2}\right) \cdot\left(c^{2}-d^{2}\right)=(a c+b d)^{2}-(a d+b c)^{2}$ . By induction on the number of edges the result follows.

Theorem 2.4: The graph $G=K_{2}+m_{1}$ is a square difference graph. 
$\left\{\mathrm{u}_{1}, \mathrm{u}_{2}\right\}$. Let us define $\mathrm{f:} \mathrm{V}(\mathrm{G}) \rightarrow\{0,1, \ldots, \mathrm{m}+1\}$ by $\mathrm{f}\left(\mathrm{u}_{\mathrm{i}}\right)=$ $\mathrm{i}-1,1 \leq \mathrm{i} \leq \mathrm{m}+2$ and the induced function $\mathrm{f}^{*}: \mathrm{E}(\mathrm{G}) \rightarrow \mathrm{N}$ defined by $f^{*}\left(u_{1}\right.$ ui $)=(i-1)^{2}, 2 \leq i \leq m+2$ and $f^{*}\left(u_{2} u j\right)=(j$ $-1)^{2}-1,2 \leq \mathrm{j} \leq \mathrm{m}+2$. All the values of are are distinct and it is an injective function. Hence it follows $\mathrm{f}$ admits square difference labeling. Hence $G$ is a square difference graph.

The following figure illustrates the theorem for $\mathrm{m}=4$.

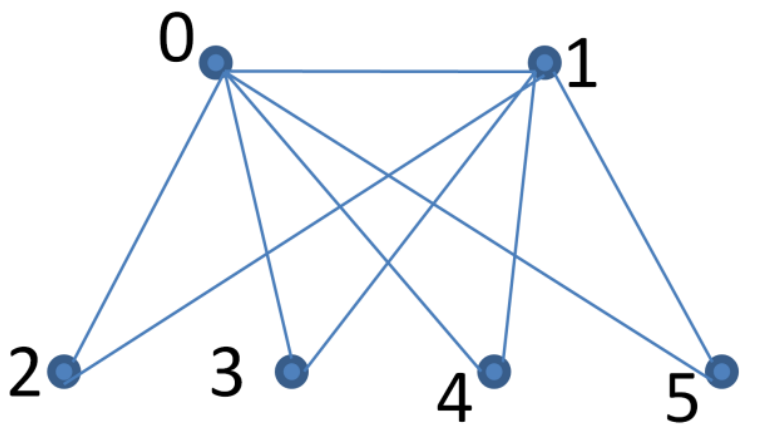

Fig.2: square difference labeling of $k_{2}+4 k_{1}$

Theorem 2.5: The complete graph $K_{n}$ is a square difference graph if and only if $\mathrm{n} \leq 5$

Proof: Let $\mathrm{V}(\mathrm{G})=\{0,1, \ldots . \mathrm{n}-1\}$ and let us define $\mathrm{f:} \mathrm{V}(\mathrm{G}) \rightarrow\{0,1, \ldots, \mathrm{n}-1\}$ by $\mathrm{f}\left(\mathrm{u}_{\mathrm{i}}\right)=\mathrm{i}-1,1 \leq \mathrm{i} \leq \mathrm{n}-1$. and the induced function $\mathrm{f}^{*}: \mathrm{E}(\mathrm{G}) \rightarrow \mathrm{N}$ defined by $\mathrm{f}^{*}(\mathrm{xy})=$ $\left|\left[f^{*}(x)\right]^{2}-\left[f^{*}(y)\right]^{2}\right|$. For $n=5$ all the edges have distinct values. But when $n=6$ we get $5^{2}-4^{2}=9$ and $3^{2}-0^{2}=9$. Similarly for $\mathrm{n}=7$, any two edge values are same. Hence the complete graph $\mathrm{K}_{\mathrm{n}}$ for $\mathrm{n} \leq 5$ admits square difference labeling. Hence $\mathrm{k}_{\mathrm{n}}$ is a square difference graph if and only if $\mathrm{n} \leq 5$.

Theorem 2.6: Cycles are Square difference graphs.

Proof: Let $C_{k}$ be a cycle of length $k$ and let $C_{k}=\left(u_{1} u_{2}\right.$, $\left.\ldots \mathrm{u}_{\mathrm{k}} \mathrm{u}_{1}\right)$ Define $\mathrm{f}: \mathrm{V}\left(\mathrm{C}_{\mathrm{k}}\right) \rightarrow\{0,1, \ldots \mathrm{k}-1\}$ as $\mathrm{f}\left(\mathrm{u}_{\mathrm{i}}\right)=\mathrm{i}-$ $1,1 \leq \mathrm{i} \leq \mathrm{k}$ and the induced funcion $\mathrm{f}^{*}: \mathrm{E}\left(\mathrm{C}_{\mathrm{k}}\right) \rightarrow \mathrm{N}$ having distinct values and is also an increasing function on $\mathrm{E}\left(\mathrm{C}_{\mathrm{k}}\right)$. Thus for any edge $f^{*}\left(e_{i}\right) \neq f^{*}\left(e_{j}\right), i \neq j$. Hence $f$ admits a square difference labeling on $\mathrm{C}_{\mathrm{k}}$. Hence cycles are Square difference graphs.
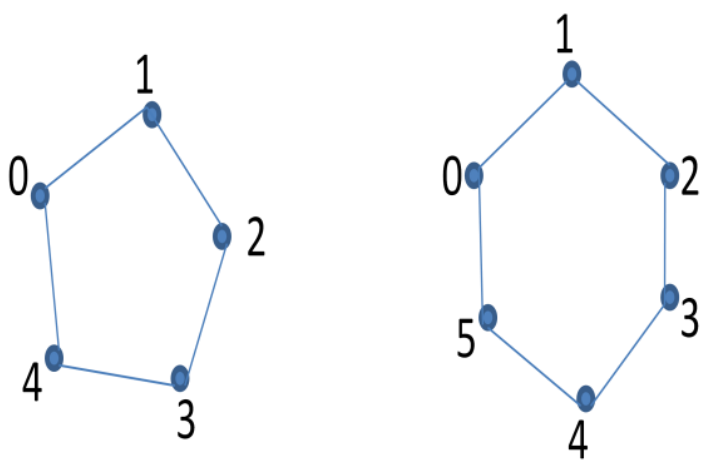

Fig.3: square difference labeling of $\mathrm{C}_{5} \& \mathrm{C}_{6}$

Theorem 2.7: Quadrilateral snakes are square difference graph.

Proof: Consider $S_{4, n}$ with vertices labeled as in its definition .

We define a function $\mathrm{f}: \mathrm{V}(\mathrm{G}) \rightarrow\{0,1, \ldots, 3 \mathrm{n}\}$ by $\mathrm{f}\left(\mathrm{u}_{\mathrm{i}}\right)=$ $3 \mathrm{i}, \mathrm{i} \in\{0,1,2, \ldots, \mathrm{n}\}$

$f\left(v_{i}\right)=3 i-1, i \in\{1,2, \ldots, n\}$
$f\left(w_{i}\right)=3 i-2, i \in\{1,2, \ldots, n\}$

And the induced function $\mathrm{f}^{*}: \mathrm{E}(\mathrm{G}) \rightarrow \mathrm{N}$ defined by by $\mathrm{f}^{*}(\mathrm{uv})=\left|[\mathrm{f}(\mathrm{u})]^{2}-[\mathrm{f}(\mathrm{v})]^{2}\right|$ for every uv $\in \mathrm{E}(\mathrm{G})$ are all distinct. Hence $S_{4, n}$ are square difference graph.

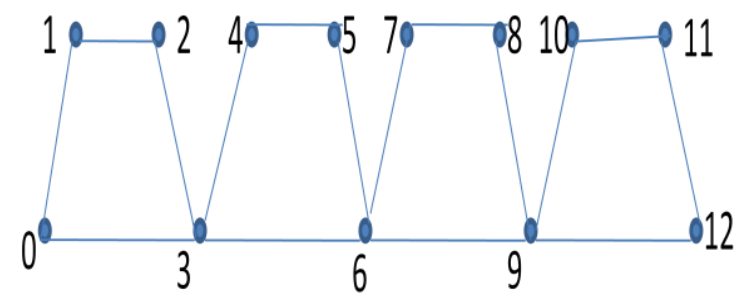

Fig.4: square difference labeling of $S_{4, n}$

Theorem 2.8: The Cycle cactus $C_{k}^{(n)}$ is a square difference graph.

Proof: Let $\mathrm{C}_{\mathrm{k}}{ }^{(\mathrm{n})}$ be the cycle cactus consisting of $\mathrm{n}$ copies of the cycle $C_{k}$. Let the cycles be denoted by $G_{1}, G_{2}, \ldots, G$ $\mathrm{n}$. All the cycles meet at one vertex, let it be $\mathrm{x}$. Let us define $\mathrm{f}$ : $\mathrm{V}\left(\mathrm{C}_{\mathrm{k}}{ }^{(\mathrm{n})}\right) \rightarrow\{0,1, \ldots, \mathrm{p}-1\}$ as follows $\mathrm{f}\left(\mathrm{u}_{\mathrm{i}}\right)=\mathrm{i}, 1 \leq \mathrm{i} \leq \mathrm{n}$ and $f(x)=0$ and the induced function $\mathrm{f}^{*}$ defined $\mathrm{f}^{*}: \mathrm{E}\left(\mathrm{C}_{\mathrm{k}}\right) \rightarrow \mathrm{N}$ by $f^{*}(\mathrm{uv})=\left|[\mathrm{f}(\mathrm{u})]^{2}-[\mathrm{f}(\mathrm{v})]^{2}\right|$ for every edge uv $\in \mathrm{E}(\mathrm{G})$ are all distinct and is a one to one function. Hence The Cycle cactus $\mathrm{C}_{\mathrm{k}}{ }^{(\mathrm{n})}$ is a square difference graph. 

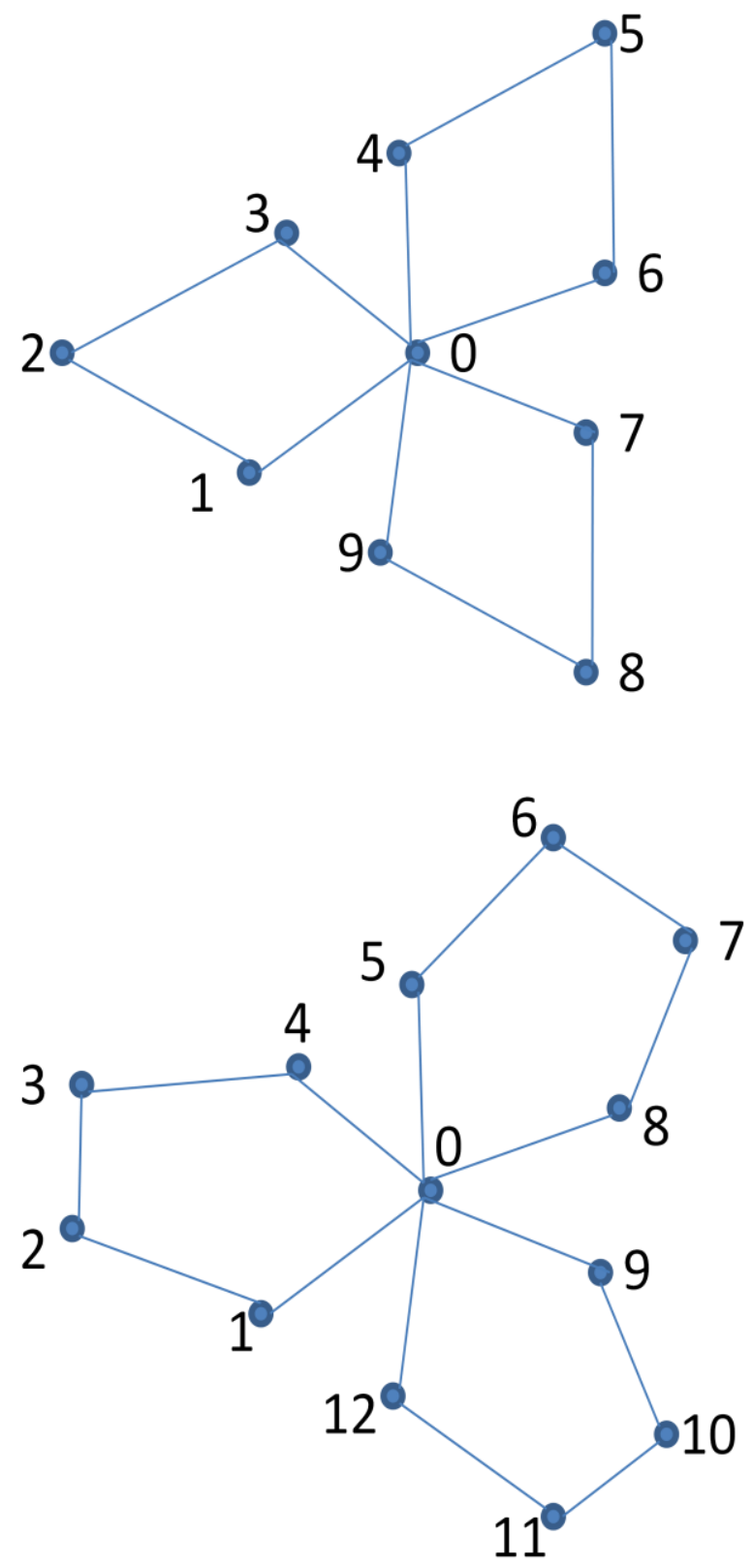

Fig.4: square difference labeling of cycle cactus

Theorem 2.9: The ladder $L_{n}$ : $=P_{n} \times k_{2}$ is a square difference

graph.

Proof: Let $V\left(\mathrm{~L}_{\mathrm{n}}\right)=\left\{\mathrm{u}_{1}, \mathrm{u}_{2}, \ldots \mathrm{u}_{\mathrm{n}}, \mathrm{v}_{1}, \mathrm{v}_{2}, \ldots, \mathrm{v}_{\mathrm{n}}\right\}$. Here $\mathrm{V}\left(\mathrm{L}_{\mathrm{n}}\right) \mid=2 \mathrm{n}$ and $\left|\mathrm{E}\left(\mathrm{L}_{\mathrm{n}}\right)\right|=3 \mathrm{n}+1$. Define $\mathrm{f}: \mathrm{V}\left(\mathrm{L}_{\mathrm{n}}\right) \rightarrow\{0,1, \ldots$ ,p-1 $\}$ as follows. $\mathrm{f}\left(\mathrm{u}_{\mathrm{i}}\right)=2 \mathrm{i}-2,1 \leq \mathrm{i} \leq \mathrm{n}$ and $\mathrm{f}\left(\mathrm{v}_{\mathrm{i}}\right)=2 \mathrm{i}-1,1$ $\leq \mathrm{i} \leq \mathrm{n}$..Hence we get $\mathrm{f}^{*}\left(\mathrm{u}_{\mathrm{i}} \mathrm{v}_{\mathrm{i}}\right)=\mathrm{u}_{\mathrm{i}}{ }^{2}-\mathrm{v}_{\mathrm{i}}{ }^{2}, 1 \leq \mathrm{i} \leq \mathrm{n}$ and $f^{*}\left(u_{i} u_{i+1}\right)=u_{i}^{2}-u_{i+1}^{2}, 1 \leq i \leq n$ also $f^{*}\left(v_{i} v_{i+1}\right)=v_{i+1}^{2}-v_{i}^{2}, 1$ $\leq \mathrm{i} \leq \mathrm{n}$ Since these numbers form an increasing sequence, $\mathrm{f}^{*}$ is injective and $\mathrm{f}$ is a square difference labeling.

The following figure-5 gives a square difference labeling

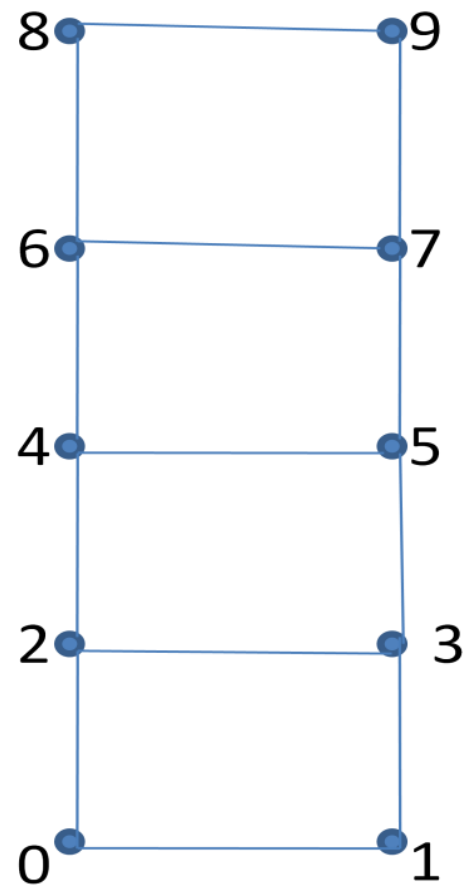

Fig.5: square difference labeling of $\mathrm{L}_{5}$

Theorem 2.10: The complete lattice grids $L_{m n}:=P_{m} \times P_{n}$ are square difference graphs.

Proof: Let $\mathrm{G}$ be the grid with $\mathrm{V}(\mathrm{G})=\left\{\mathrm{u}_{11}, \mathrm{u}_{12}, \ldots, \mathrm{u}_{1 \mathrm{n}}, \mathrm{u}_{21}\right.$ $\left., \mathrm{u}_{22}, \ldots, \mathrm{u}_{2 \mathrm{n}}, \ldots, \mathrm{u}_{\mathrm{m} 1}, \mathrm{u}_{\mathrm{m} 2}, \ldots, \mathrm{u}_{\mathrm{mn}}\right\}$.let $\mathrm{us}$ arrange the set of vertices of $\mathrm{G}$ into different levels as follows:

Define $f: V(G) \rightarrow\{0,1, \ldots, m . n-1\}$ by

$\mathrm{f}\left(\mathrm{u}_{11}\right)=0, \mathrm{f}\left(\mathrm{u}_{12}\right)=1, \mathrm{f}\left(\mathrm{u}_{13}\right)=2, \mathrm{f}\left(\mathrm{u}_{14}\right)=3, \mathrm{f}\left(\mathrm{u}_{15}\right)=4, \mathrm{f}\left(\mathrm{u}_{21}\right)=5$ and so on. Then the induced edge labeling given by $\mathrm{f}^{*}(\mathrm{e})=$ $\left|\left[\mathrm{f}^{*}(\mathrm{u})\right]^{2}-\left[\mathrm{f}^{*}(\mathrm{v})\right]^{2}\right| \forall \mathrm{e} \in \mathrm{E}(\mathrm{G})$, is injective, for if let $\mathrm{e}_{1}=\mathrm{u}_{1} \mathrm{v}_{1}$ and $e_{2}=u_{2} v_{2}$ be any two edges of $G$ then $f^{*}\left(e_{1}\right) \neq f^{*}\left(e_{2}\right)$ so that $\mathrm{f}^{*}$ is a square difference labeling of $\mathrm{G}$.

Hence $\mathrm{G}$ is a square difference graph.

The following figure shows the square difference labeling of $\mathrm{L}_{45}=\mathrm{P}_{4} \times \mathrm{P}_{5}$ 


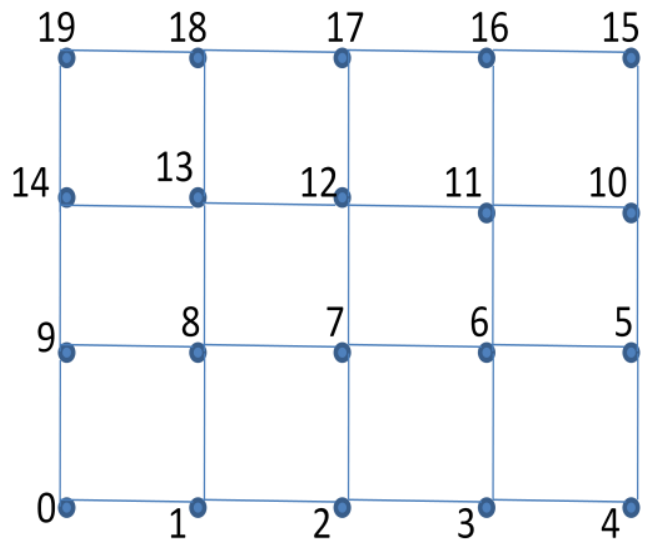

Fig.6: square difference labeling of $\mathbf{L}_{4,5}$

Theorem 2.11: The Wheel graph $W_{n}$ admits a square difference graphs for $\mathrm{n} \leq 4$.

Proof: Let $\mathrm{G}$ be the wheel $\mathrm{W}_{\mathrm{n}}$ with $|\mathrm{V}(\mathrm{G})|=\mathrm{n}+1$ and $\mid$ $\mathrm{E}(\mathrm{G}) \mid=2 \mathrm{n}$. Define $\mathrm{f}: \mathrm{V}(\mathrm{G}) \rightarrow\{0,1,2,3,4 \ldots \ldots \ldots, \mathrm{n}\}$ by $\mathrm{f}\left(\mathrm{u}_{\mathrm{i}}\right)=\mathrm{i}-1$ for $1 \leq \mathrm{i} \leq \mathrm{n}$ and the induced function $\mathrm{f}^{*}: \mathrm{E}\left(\mathrm{W}_{\mathrm{n}}\right) \rightarrow$ $\mathrm{N}$ defined by $\mathrm{f}^{*}(\mathrm{uv})=\left|[\mathrm{f}(\mathrm{u})]^{2}-[\mathrm{f}(\mathrm{v})]^{2}\right|$ for every uv $\in \mathrm{E}(\mathrm{G})$ are all distinct. and is also an increasing function on $\mathrm{E}\left(\mathrm{W}_{\mathrm{n}}\right)$. Thus for any edge $f^{*}\left(e_{i}\right) \neq f^{*}\left(e_{j}\right), i \neq j$. Hence $f$ admits a square difference labeling on $\mathrm{C}_{\mathrm{k}}$. Hence wheels are Square difference

graphs.

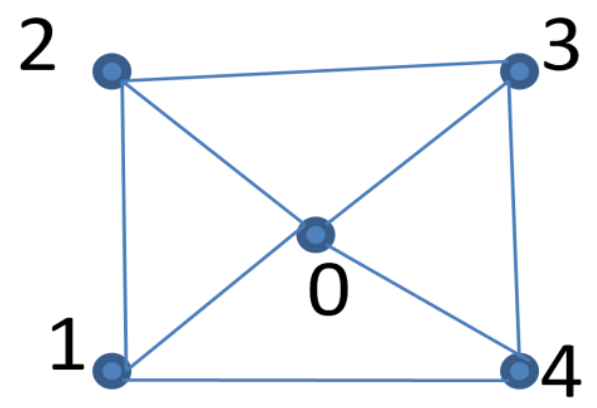

Fig.7: square difference labeling of $W_{4}$

\section{CONCLUSION}

Square difference labeling is a new concept introduced by me. In this paper I investigated some graphs like cycle, cycle cactus, ladder, lattice grids, wheels, Quadrilateral snakes, complete graph $\mathrm{K}_{\mathrm{n}}$, are Square difference graphs. For many other graphs this labeling can be verified.

\section{ACKNOWLEDGEMENTS}

The author is thankful to the referee for the valuable comments which improves the standard of the paper.

\section{REFERENCES}

[1]V.Ajitha, S.Arumugam and K.A.Germina "On Square sum graphs" AKCE J.Graphs, Combin, 6(2006) 1- 10

[2] L.Beineke and S.M.Hegde, Strongly multiplicative graphs, Discuss. Math. Graph theory, 21(2001), 63- 75.

[3] Frank Harrary, Graph theory, Narosa Publishing House(2001).

[4] J A Gallian, A dynamic survey of graph labeling, The Electronics journal of Combinatories, 17(2010) \# DS6

[5]Gary Chartrnd, Ping Zhang, Introduction to Graph theory, McGraw- Hill International Edition

[6] J.Shiama" Square sum labeling for some middle and total graphs" International Journal of Computer Applications (0975-08887) Volume 37- No.4 January 2012

[7] J.Shiama "Permutation labeling for some shadow graphs" International Journal of Computer Application (09758887) Volume 40- No.6 February 2012

[8] J.Shiama "Permutation labeling for some splitting graphs" Proceedings of the National Conference on Mathematical Modeling and Simulation. NCMS' $1211^{\text {th }}$ Feb.2012, by Vinayaka missions.

[9]D B West, Introduction to Graph Theory, Prentice-Hall, India, 2001 